\title{
Knowledge Awareness and Attitude about Research Ethics among Dental Faculties in India
}

\author{
${ }^{1}$ Nithin Manchery Gopinath, ${ }^{2}$ Joseph John, ${ }^{3} \mathrm{E}$ Senthilkumar, ${ }^{4} \mathrm{~N}$ Nagappan
}

\section{ABSTRACT}

Aim: The aim of this study was to assess the level of knowledge, awareness and attitude about research ethics and research ethics committees (RECs) among dental faculties.

Materials and methods: This cross-sectional questionnaire study incorporated a self administered questionnaire. Descriptive, Chi-square and logistic regression analysis was used to analyze the data.

Results: The overall response rate to the study was $85 \%$. More than half were familiar with research ethics, principles and functions of the research ethics committee. Though there were some faculties whose attitude regarding research ethics principle was not optimal.

Conclusion: The present study revealed a broad acceptance among the faculties acceptance toward RECs and training in research ethics, though there existed certain gap in knowledge about research among the faculties.

Clinical significance: This will help us to understand the knowledge, awareness and attitudes of dental faculties toward research ethics, which will help the institutional officials to develop better educational programs in the field of research ethics in order to help them conduct better research henceforth.

Keywords: Dental research, Ethics, Faculties, India.

How to cite this article: MG Nithin, John J, Senthilkumar E, Nagappan N. Knowledge Awareness and Attitude about Research Ethics among Dental Faculties in India. J Contemp Dent Pract 2014;15(5):608-613.

Source of support: Nil

Conflict of interest: None

\footnotetext{
1,3,4 Senior Lecturer, ${ }^{2}$ Professor and Head

${ }^{1,3}$ Department of Public Health Dentistry, Madha Dental College and Hospital, Chennai, Tamil Nadu, India

${ }^{2}$ Department of Public Health Dentistry, Saveetha Dental College and Hospital, Chennai, Tamil Nadu, India

${ }^{4}$ Department of Public Health Dentistry, Chettinad Dental College and Hospital, Chennai, Tamil Nadu, India
}

Corresponding Author: Nithin Manchery Gopinath, Senior Lecturer, Department of Public Health Dentistry, Madha Dental College and Hospital, Madha Nagar, Somangalam Road Kundrathur, Chennai-600069, Tamil Nadu, India, Phone: 9884534843, e-mail: dr.nithinmg@gmail.com

\section{INTRODUCTION}

Dental research has been evolving at a rapid pace globally. During the past years there have been remarkable advancements in the field of dentistry owing to the development of newer technologies and this is due to the considerable amount of research which is being carried out.

Medical research has increased greatly in many developing countries during the recent decade, motivated by the need to improve health in these countries. ${ }^{1}$ Since medical research involves human participants, such research needs to be guided by fundamental ethical principles to ensure the protection of their rights, integrity and welfare. Furthermore, international standards mandate the review of research by Research Ethics Committees (RECs). ${ }^{2,3}$

The field of dentistry is no less and is committed to several researches investigating the causes and treatment of dental diseases and adheres to the same ethical standards embraced by the fields of medicine. ${ }^{4}$ However, concerns have been expressed regarding the adequacy of ethics review systems in developing countries.

In general, commentators have voiced concerns that RECs in developing countries might not be able to promote high standards of human subject protection due to inadequate financial and material resources, lack of adequately trained REC members, insufficient diversity of membership, lack of REC independence and inability to monitor approved protocols. ${ }^{5,6-8}$

The scenario of dental research in India in recent years has undergone a rapid transformation. This is evident by the ever increasing number of manuscripts that are being published in various Indian and International dental journals. India had been ranked 26th position in terms of number of peer reviewed published dental manuscripts in the period 1999 to 2003 using ISI database approach $(0.66 \%$ of all contribution globally). However, there has been little research which has investigated the attitudes of dental faculty toward concepts of research ethics, including the acceptability of RECs and their desire for training in research ethics in India, which hence formed the aim of this study.

\section{MATERIALS AND METHODS}

India has the largest number of dental colleges in the world (294), and a large contribution is made by the faculties of these dental colleges toward research. 
This cross-sectional survey study was conducted during the period between April and June 2012.

Majority of dental research in India are carried out by academic staffs and postgraduates. The faculties also play a prominent role in guiding the postgraduates to conduct proper research. This study used a sample of convenience.

The study recruited members of the dental faculty (professors, reader and lecturers) at Saveetha University, Chennai, India.

Prior to the start of the study, ethical clearance was obtained from the Institutional Ethics Committee. To ensure anonymity, the RECs waived the requirement of signed written consent, completion of the survey implied participant's provision of informed consent.

Based on previous articles of similar studies, the sample size of 96 (95\% power @ 5\% alpha) was determined and only those faculties with 2 years and above of teaching experience and who were interested to participate were included.

We distributed 96 survey forms to faculty members. The faculty was asked to return the surveys back anonymously by placing it in a drop box, which was placed outside each department.

Survey instrument: A pretested, structured questionnaire ${ }^{9}$ was used. The survey tool consisted of several parts.

The first section collected demographic information of the participants such as age, gender, academic position, prior participation in human subject's research, number or research projects involved in and prior training in research ethics. No details were asked regarding any workshops or courses the faculty had attended.

The second part assessed the participants self awareness of research ethics, principles and functions of research ethics committees. The third section of the questionnaire assessed participant's knowledge and attitude toward research ethics, which also consisted of several case scenarios involving

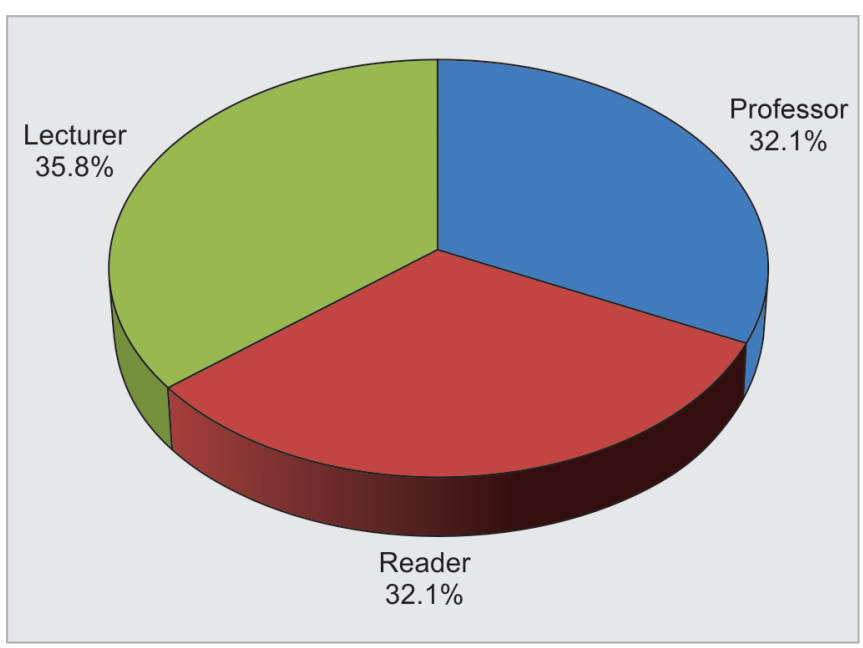

Graph 1: Distribution of study subjects based on academic position the ethics of clinical research in dentistry and asking the respondents to answer questions based on them.

The last section of the survey assessed participant's attitude toward REC. Respondents were required to choose from a 5-point Likert scale ranging from 1 to 5 (1-strongly agree, 2-agree, 3-not sure, 4-disagree, 5-strongly disagree).

Data was entered in microsoft excel spread sheet and analyzed using SPSS software (version 18).

\section{RESULTS}

Of the 96 faculties 81 responded, of which 43 (53.1\%) were males and $38(46.9 \%)$ were females. The age group of the study subjects ranged from 25 to 64 years.

The distribution of study subjects based on academic position is shown in Graph 1.

The percentage of faculty performing research on human subjects was similar among the professors (81\%) and readers $(81 \%)$ while it was $48 \%$ among the lecturers.

The distribution of study subjects based on academic position to prior research experience and ethical training is shown in Table 1. Faculty with prior research experience was found to be equal while some difference existed between ethical training among the faculties.

The distribution of study subjects based on level of knowledge in research ethics is depicted in Graph 2.

The respondents responses regarding their awareness of research ethics and REC is shown in Table 2. Faculty with 'prior research experience' were significantly more likely to state that they were familiar with research ethics principles $(p<0.01)$. Regarding awareness of the functions of the ethical committee there was a statistical significance to academic position $(\mathrm{p}<0.05)$.

A multiple logistic regression analysis was performed to determine which independent variables were the strongest

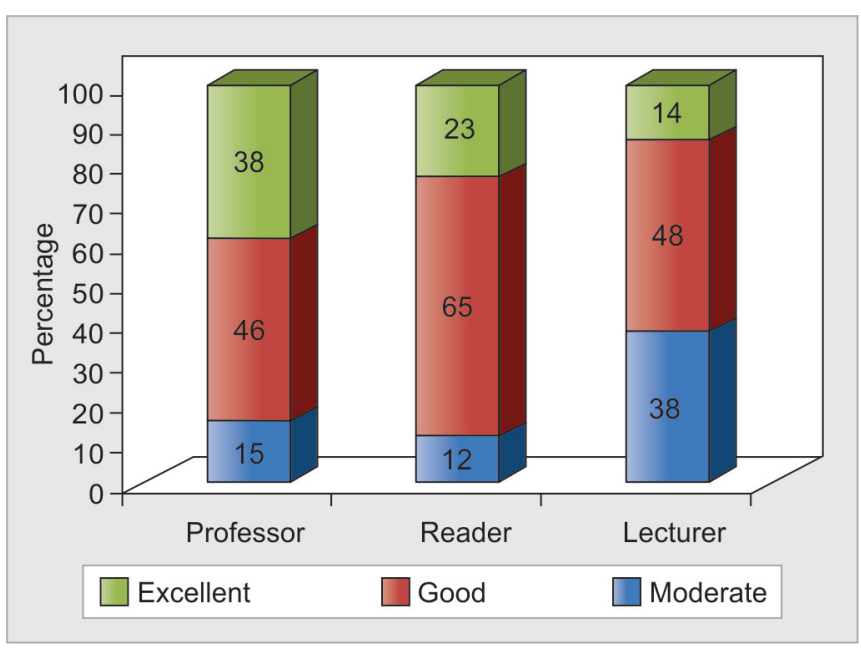

Graph 2: Distribution of study subjects based on level of knowledge in research ethics 
Table 1: Distribution of study subjects based on academic position to prior research experience and ethical training

\begin{tabular}{|c|c|c|c|c|c|c|c|c|c|c|}
\hline \multirow{3}{*}{$\begin{array}{l}\text { Academic } \\
\text { position }\end{array}$} & \multicolumn{4}{|c|}{ Prior research experience } & \multicolumn{4}{|c|}{ Had ethical training } & \multicolumn{2}{|c|}{ Total } \\
\hline & \multicolumn{2}{|c|}{ Yes } & \multicolumn{2}{|c|}{ No } & \multicolumn{2}{|c|}{ Yes } & \multicolumn{2}{|c|}{ No } & \multirow[t]{2}{*}{$N$} & \multirow[t]{2}{*}{$\%$} \\
\hline & $N$ & $\%$ & $N$ & $\%$ & $N$ & $\%$ & $N$ & $\%$ & & \\
\hline Professor & 22 & 31.4 & 4 & 36.4 & 16 & 38.1 & 10 & 25.6 & 26 & 32.1 \\
\hline Reader & 24 & 34.3 & 2 & 18.2 & 14 & 33.3 & 12 & 30.8 & 26 & 32.1 \\
\hline Lecturer & 24 & 34.3 & 5 & 45.5 & 12 & 28.6 & 17 & 43.6 & 29 & 35.8 \\
\hline Total & 70 & 100 & 11 & 100 & 42 & 100.0 & 39 & 100 & 81 & 100 \\
\hline
\end{tabular}

Table 2: Awareness of research ethics and research ethics committee among faculties: aggregate responses and association between responses and independent variables

\begin{tabular}{|c|c|c|c|c|c|c|c|c|c|c|c|c|c|c|c|}
\hline \multirow[t]{3}{*}{ Item } & & \multicolumn{6}{|c|}{ Academic position } & \multicolumn{4}{|c|}{ Prior research experience } & \multicolumn{4}{|c|}{ Had ethical training } \\
\hline & & \multicolumn{2}{|c|}{ Professor } & \multicolumn{2}{|c|}{ Reader } & \multicolumn{2}{|c|}{ Lecturer } & \multicolumn{2}{|c|}{ Yes } & \multicolumn{2}{|c|}{ No } & \multicolumn{2}{|c|}{ Yes } & \multicolumn{2}{|c|}{ No } \\
\hline & & $N$ & $\%$ & $N$ & $\%$ & $N$ & $\%$ & $N$ & $\%$ & $N$ & $\%$ & $N$ & $\%$ & $N$ & $\%$ \\
\hline \multirow{2}{*}{$\begin{array}{l}\text { Familiar with ethical principles } \\
\text { of research involving human } \\
\text { subjects* }\end{array}$} & No & 3 & 11.5 & 4 & 15.4 & 10 & 34.5 & 11 & 15.7 & 6 & 54.5 & 6 & 14.3 & 11 & 28.2 \\
\hline & Yes & 23 & 88.5 & 22 & 84.6 & 19 & 65.5 & $59^{*}$ & 84.3 & 5 & 45.5 & 36 & 85.7 & 28 & 71.8 \\
\hline \multirow{2}{*}{$\begin{array}{l}\text { Know any committee/ } \\
\text { organization that review ethical } \\
\text { aspects of research }\end{array}$} & No & 4 & 15.4 & 2 & 7.7 & 8 & 27.6 & 13 & 18.6 & 1 & 9.1 & 8 & 19.0 & 6 & 15.4 \\
\hline & Yes & 22 & 84.6 & 24 & 92.3 & 21 & 72.4 & 57 & 81.4 & 10 & 90.9 & 34 & 81.0 & 33 & 84.6 \\
\hline \multirow{2}{*}{$\begin{array}{l}\text { Think that the existence of } \\
\text { ethics committee would be } \\
\text { helpful }\end{array}$} & No & 2 & 7.7 & 1 & 3.8 & 3 & 10.3 & 5 & 7.1 & 1 & 9.1 & 3 & 7.1 & 3 & 7.7 \\
\hline & Yes & 24 & 92.3 & 25 & 96.2 & 26 & 89.7 & 65 & 92.9 & 10 & 90.9 & 39 & 92.9 & 36 & 92.3 \\
\hline \multirow{2}{*}{$\begin{array}{l}\text { Aware of the functions of } \\
\text { ethical committee }\end{array}$} & No & 8 & 30.8 & 15 & 57.7 & 18 & 62.1 & 36 & 51.4 & 5 & 45.5 & 18 & 42.9 & 23 & 59.0 \\
\hline & Yes & $18^{* *}$ & 69.2 & 11 & 42.3 & 11 & 37.9 & 34 & 48.6 & 6 & 54.5 & 24 & 57.1 & 16 & 41.0 \\
\hline
\end{tabular}

${ }^{*} \chi^{2} ; 8.64 ; \mathrm{df}=1(\mathrm{p}<0.01) ;{ }^{* *} \chi^{2}: 6.14 ; \mathrm{df}=2(\mathrm{p}<0.05)$

predictors of the responses in Table 3. The analysis showed that prior research experience was a strong predictor for stating a familiarity with research ethics principle $(\mathrm{p}<0.05$, OR 6.52; 95\% CI, 1.429-29.783).

The Table 3 shows the respondents attitude toward REC and research ethics education. A large majority of the respondents (greater than 93\%) were in favor of research ethics education for postgraduates, investigators and members of RECs. Less than $20 \%$ of the faculties felt that ethical review is only necessary for international collaborative projects and the presence of scientific committee made the existence of an REC unnecessary. The percentage of faculty which felt that review by research ethics committee would make it harder and delay research was highest among the lecturers $9(31.0 \%)$, readers $6(23.1 \%)$ followed by the professors who constituted the least $2(7.7 \%)$.

Of note, faculty with prior research experience were significantly more likely to believe that human subject research must be reviewed by an REC $(p<0.05)$. None of the independent variables were strong predictors for any of these attitudes.

All of the respondents believed in the need for confidentiality protection of research participant's data. More than $95 \%$ of the respondents believed that the patients should be informed regarding the risks and benefits of research. Only a mere $12 \%$ of the respondents felt it was proper to fabricate data to improve the outcome of research if such an act did not cause any harm to the patients. A large majority $(>85 \%)$ of the respondents thought that vulnerable groups, such as children and mentally ill could not provide informed consent.

Faculty with prior research experience were significantly more likely to believe that human subject research must be reviewed by an REC $(\mathrm{p}<0.05)$.

\section{DISCUSSION}

In recent years there has been an increase in dental research in the developing countries, including India. The field of dentistry adheres to the same ethical standards embraced by the fields of medicine, so concepts of research ethics have gained importance. ${ }^{4}$ Research investigators should be aware of the ethical, legal and regulatory requirements for research on human subjects in their own countries as well as applicable to international requirements. ${ }^{2}$

This survey was carried out to highlight the level of knowledge, awareness and attitude about research and REC among the dental faculties in India. The study showcases several findings which could be of use to institutional officials to understand better and develop relevant educational programs in research ethics directed toward the dental faculty.

The surveyed dental faculties were in acceptance for the existence of REC in universities, as all were of the opinion that such committees would be helpful in conducting and reviewing research in a proper manner. The findings of the present survey were in accordance to some previous studies, which was with regard to the acceptance of RECs among 


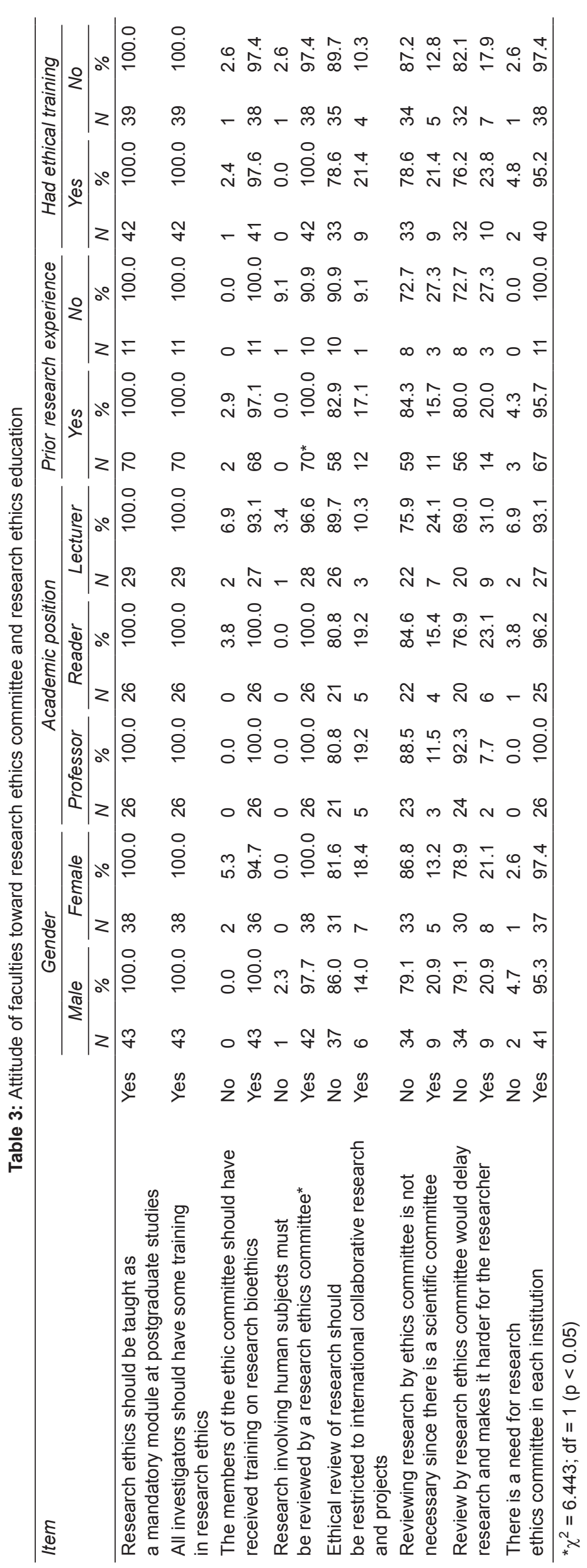


academics conducted in Sudan by Elsayed ${ }^{10}$ in 2007 and in Egypt by N Asem ${ }^{11}$ in 2009.

In the present study very few respondents felt that a REC would delay research, the opinion being held high among the lecturers. The possible reason for this could be having unfavorable experiences with REC. This was in contrast to the findings of the study done by Hadir. F9 in 2011 where the mid level faculty with prior ethics training believed that an REC would delay research.

The survey carried out also brings to notice the attitudes of dental faculty toward certain practices in research ethics. A large percentage of the faculties were aware of the practices regarding confidentiality protection and several aspects of the informed consent process. This result was in difference with concerns mentioned regarding informed consent practices by AM Rashad. ${ }^{12}$ However, an important finding regarding informed consent was regarding the vulnerable groups. A majority ( $>85 \%)$ of the respondents were of the opinion that vulnerable groups such as children and mentally ill could not provide informed consent. This was in contrast to the study by Hadir F9 were only a relatively less number of respondents felt so. This can be attributed to the poor understanding of several key elements of the informed consent process.

Only $12 \%$ of the respondents thought it was acceptable to fabricate data and lecturers were more in favor of this opinion compared to the other faculties. This percentage was similar to some previous studies. A study of biomedical trainees done by Michael W Kalichaman ${ }^{13}$ in 1992 at University of California, San Diego, showed that 15\% admitted of personal misconduct and they were willing to fabricate, select or omit data for publishing a paper or obtaining a research grant. Reason that may account for this difference between the levels of faculties may be due to the lack of experience and training in research practices in comparison to the senior faculties.

Our survey also yielded important results regarding training capacity in research ethics. More than half (42\%) of the 81 respondents of the university had received prior training in research ethics.

The level of knowledge about research ethics was considerably better for the higher level faculties (Professor and readers) than the lecturers. This was in contrast to the findings of the study by Hadir F9 in which the mid-level faculty scored better. Several reasons could be offered to explain this result, first the percentage of lecturers who had received prior ethics training were less compared to other faculty, other reason may be due to lack of experience. Further studies have to be carried in depth to account for these differences in knowledge gap between the faculties.
The present study also showed that all faculty levels were favorable toward research ethics training for postgraduates, investigators and REC members, though previous studies have had mixed results regarding the effects of ethics education on knowledge. Further research is needed to determine the teaching methods that are most effective in addressing the existing knowledge gaps in research ethics.

There were limitations to this study. The data being self reported and the subjects may have responded in a socially desirable manner.

\section{CONCLUSION}

The findings of the present study show that though there exists some gap in knowledge about research, there was a wide acceptance for RECs and training in research ethics among the dental faculties. Furthermore, there is an important need to implement educational instruction in research ethics for the entire faculty with special emphasis on informed consent, role and functions of RECs. Such efforts can lead to enhanced knowledge and acceptance of research ethics principles among investigators.

\section{CLINICAL SIGNIFICANCE}

This will help the institutional officials to develop better educational programs in the field of research ethics which would further help to improve understanding of ethical principles thereby helping the faculties to conduct and guide research in a more appropriate manner.

\section{ACKNOWLEDGMENT}

The authors would like to thank all the faculties who participated in study.

\section{REFERENCES}

1. Normile D. 'The promise and pitfalls of clinical trials overseas'. Science 2008 Oct;322(5899):214-216.

2. World Health Organization [Internet] Declaration of Helsinki-Ethical Principles for Medical Research Involving Human Subjects; [2008]. Available at: http://www.wma.net/ en/30publications/10policies/b3/index.html.

3. Council for International Organizations of Medical Sciences (CIOMS), International Ethical Guidelines for Biomedical Research Involving Human Subjects, Council for International Organizations of Medical Sciences, Geneva, Switzerland; 2002.

4. Gillett GR. 'Ethics and dental research,' J Den Res 1994 Nov; 73(11):1766-1772.

5. Hyder AA, Wali SA, Khan AN, Teoh NB, Kass NE, Dawson L. Ethical review of health research: a perspective from developing country researchers. J Med Ethics 2004 Feb;38:68-72.

6. Sumathiapala A, Siribaddana S, Patel V. Under-representation of developing countries in the research literature: Ethical issues arising from a survey of five leading medical journals. BMC Med Ethics 2004 Oct;5:5-10. 
7. Kass N, Hyder AA. Attitudes and experiences of US and developing country investigators regarding US human subject's regulations. In Ethical and Policy Issues in International Research: Clinical Trials in Developing Countries Volume II. Bethesda, MD: National Bioethics Advisory Commission; 2001:B1-B189.

8. Kass N, Dawson L, Loyo-Berrios NI. Ethical oversight of research in developing countries. IRB: Ethics \& Human Research 2003 Mar-Apr;25:1-10.

9. Hadir F, El-Dessouk, Abdel-Aziz AM, Ibrahim C, Moni M, Fadl RA, Silverman H. Knowledge, Awareness, and Attitudes about Research Ethics among Dental Faculty in the Middle East: A Pilot Study. Int J Den 2011.
10. Asem N, Silverman HJ. 'Perspectives of faculty at Cairo University towards research ethics and informed consent', in Proceedings of the Public Responsibility in Medicine and Research (PRIM\&R '06). Nashville, Tenn, USA; 2009.

11. Elsayed DEM, Kass NE. 'Assessment of the ethical review process in Sudan', Dev World Bioeth 2007 Dec;(7)3:143-148.

12. Rashad AM, Phipps FM, Haith-Cooper M. Obtaining infor-med consent in an Egyptian research study. Nursing Ethics, 2004; 11(4):394-399.

13. Kalichman MW, Friedman PJ. A pilot study of biomedical trainees' perceptions concerning research ethics. Acad Med 1992 Nov;67(11):769-775. 